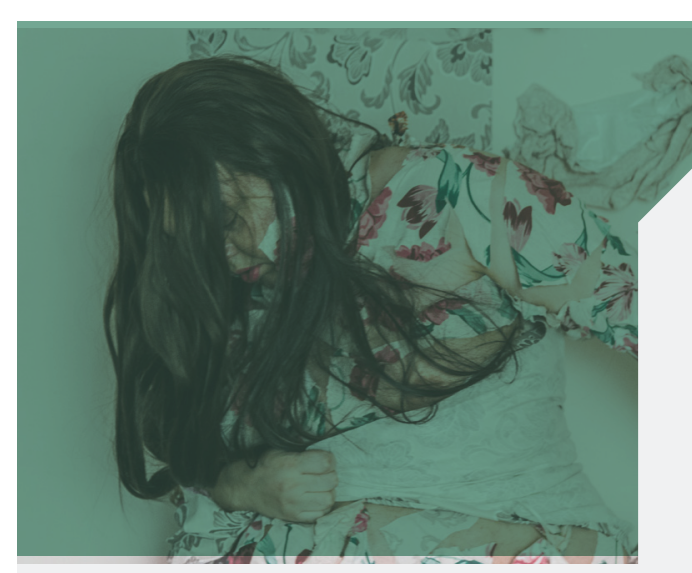

THE CATCHER IN THE RYE: UM HISTÓRICO

EDITORIAL DAS PRIMEIRAS PUBLICAÇÕES DO LIVRO

DE J. D. SALINGER NOS ESTADOS UNIDOS (1951-

1963) E DE SUA EDIÇÃO NO BRASIL (1965 E 2019)

THE CATCHER IN THE RYE:AN EDITORIAL HISTORY OF THE FIRST PUBLICATIONS OF J. D. SALINGER'S BOOK IN THE UNITED STATES (1951-1963) AND ITS PUBLICATION IN BRAZIL (1965 AND 2019)

Flávia Denise Pires de Magalhães*

\begin{abstract}
flavia.denise@gmail.com
Doutoranda em Estudos Literários pela Universidade Federal de Minas Gerais (UFMG). É mestre em Estudos de Linguagens pelo Centro Federal de Educação Tecnológica de Minas Gerais (CEFET-MG). É Bacharel em Comunicação Social pela Pontifícia Universidade Católica em Publishing na New York University (NYU).
\end{abstract}

ABSTRACT: This essay seeks to trace the Brazilian editoria history of The Catcher in the Rye, novel by J. D. Salinger. We started from the original publication in the United States (Little, Brown and Company, 1951), mapping editions of the first twelve vears of the book, in the country, which have been edited by Editora do Autor (beginning in 1965) and by Todavia (2019). An analysis of the author's influence on the book's editorial processes is made in the light of D. F. McKenzie. Finally, a comparative analysis is made of the first Brazilian edition and Todavia's edition.

KEYWORDS: Publishing; Book Cover; Salinger 
Publishing is a terrible invasion of my privacy.

J. D. Salinger

A publicação de um livro é um processo de muitas etapas, que envolve pessoas com diferentes competências específicas. Entre o momento em que o autor entrega seu texto à editor e o lançamento do livro, são realizados diversos processos editoriais. Esses processos não são meramente técnicos, mas criações que se agregam à obra e, como tal, a influenciam, podendo mudar seu sentido. Em Bibliografia e sociologia dos textos, Donald Francis McKenzie demonstra o impacto que mudanças tipográficas e o modo em que um texto é reproduzido têm na recepção. Ao longo da obra, o autor revela o pensamento por trás da máxima: "as formas afetam o significado" (2018, p.25). Nas palavras do autor:

[O objetivo é mostrar que,] em alguns casos, leituras significativamente informativas podem ser recuperadas a partir dos signos tipográficos, assim como dos verbais; que eles são relevantes às decisões editoriais sobre o modo no qual um texto será reproduzido, e que uma leitura de tais signos bibliográficos pode realmente moldar nosso julgamento da obra de um autor (MCKENZIE, 2018, p. 32).
Com isso em mente, busca mos traçar um histórico editorial do livro The catcher in the rye, de J. D. Salinger, ressaltando a importância dada aos signos bibliográficos durante os processos de edição e publicação de versões americanas e brasileiras. A comparação de edições sucessivas do livro mostra o impacto de aspectos visuais das encadernações brochuras, assim o como de outros elementos paratextuais ao longo de sua vida editorial. Esta análise revela a história de um autor famoso por ser recluso e ter se retirado do olhar público e que, ao longo de anos, parece ter tentado minimizar o impacto das criações de outros profissionais da edição ao seu livro ao impor limitações à edição da obra.

Em 1951, Jerome David Salinger (1919-2010) publicou The catcher in the rye. A história já havia sido parcialmente publicada na forma de contos. ${ }^{1}$ Nas décadas seguintes, o relato em primeira pessoa do colapso nervoso de Holden Caulfield se tornou um sucesso de vendas ${ }^{2}$ e um marco da literatura ocidental. ${ }^{3}$ A história editorial do livro começa com a recusa do editor Eugene Reynal, da editora Harcourt Brace, em publicar o romance, que havia sido encomendado pela própria casa. Louis Menand, em texto para a revista The New Yorker, periódico que havia publicado seis contos do autor antes do lançamento do livro e cujos editores também se negaram a publicar o romance, escreve que o editor "alca nçou imortalidade do jeito ruim ao recla mar que ele não
1. O conto "Slight rebellion off de dezembro de 1946 na revista norte-americana The New Yorker. "I'm crazy" foi publicado em 22 de dezembro de 1945 , na revista norte-americana Collier's.

2. Entrevista feita em 1974 pelo The New York Times com o autor cita que 250 mil cópias do (FOSBURGH, 1974, p. 1).

3. Nas palavras do crítico literário Harold Bloom em introdução de livro teorico dedicado à obra de Salinger: "The (1951): Nine stories (1953)] are minor masterpieces or minor classics and remind us that "minor" can be a descriptive as well as an evaluative word in literary criticism" (BLOOM, 2008, p. 1). 
4. No original: "achieved immortality the bad way by
complaining that he couldn't figure out whether or not Holden Caulfield was supposed to be conseguia entender se era para Holden Caulfield ser louco ou não" (MENAND, 2001, s/n). ${ }^{4}$

Figura 1: Sobrecapa da primeira edição norte-a mericana e ca nadense de The catcher in the rye

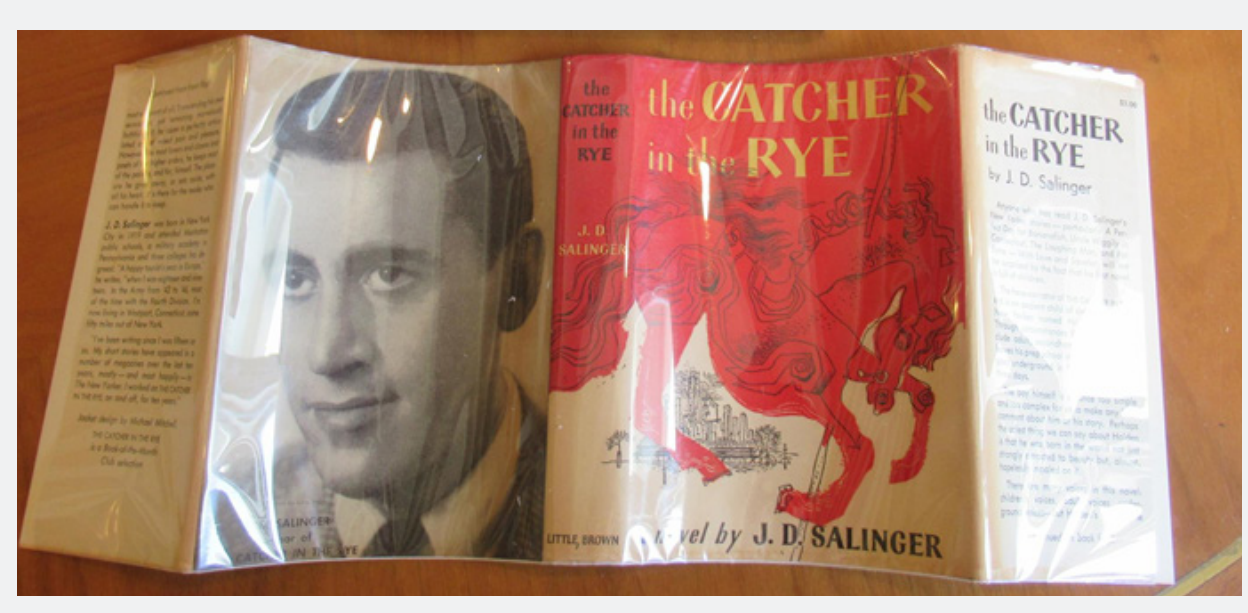

Fonte: Abe Books

Apesar da rejeição inicial, o livro foi publicado nos Estados Unidos e no Canadá em 16 julho de 1951 pela Little, Brown and Company, com edição de John Woodburn. A capa foi ilustrada por E. Michael Mitchell, a migo e vizinho de Salinger. $\mathrm{Na}$ quarta capa, uma fotografia de Salinger feita por Lotte Jacobi. O livro recebeu críticas positivas, em geral elogiando a desenvoltura do texto, e negativas, sendo que muitas, de cunho moralizante, citava $\mathrm{m}$ a grande quantidade de palavrões e o fato de o protagonista adolescente ter contato com uma prostituta como motivo para sua condenação. ${ }^{5} \mathrm{O}$ sucesso editorial imediato do romance chama atenção:

Em duas semanas, ele teve cinco tiragens, no mês seguinte, foram mais três - apesar de, na terceira edição, a fotografia do autor na quarta capa ter desaparecido silenciosamente. O livro dele ficou na lista de best-seller por trinta semanas, apesar de nunca ter passado do quarto lugar (WHITFIELD, 1997, p. 567). ${ }^{6}$

Essa presença imediata nas listas de mais vendidos é parcialmente explicada pela primeira leva de críticas e reportagens sobre o lançamento do livro, mas há outros aspectos que impulsionaram a circulação e explicam a quantidade de edições no primeiro a no de publicação da obra. O primeiro fator a ser considerado é a seleção da obra para o Book-of-the-Month Club, um clube de assina tura de livros que chegou a 1,5 milhão de assinantes na década de 1980. Em 1951, a escolha do livro de Salinger pelo Book-of-the-Month Club não só garantiu uma distribuição a todo o país, como serviu de argumento para a venda do livro para leitores que não assinava m o serviço.

O segundo fator que influenciou no sucesso das vendas do romance foi a edição em paperback - brochura de baixo custo -, publicada dois anos após a capa dura. Em Two-bit culture:
5. $O$ artigo "Cherished and cursed: toward a social history of The catcher in the rye", de Stephen J. Whitfield, detalha a recepção do livro, das críticas positivas e negativas à censura em escolas e elogios na mídia.

6. No original: "Within two weeks, it had been reprinted five times, the next month three more times - though by the third edition the jacket photograph of the author had quietly disappeared. His book stayed on the best-seller list for thirty weeks, though never above fourth place". 
7. No original: "Before these inexpensive, widely distributed books came along, only the rarest of books sold more than a hundred thousand copies [...] Overnight, the paperback changed that. Suddenly, a book could reach not hundreds or thousand of readers but millions, many of whom had never owned a book before".

8. No original: "[...] these alienated white suburban best-fed, best-clothed, and best-educated generation in history. They were also the richest. [...] The average teen had a disposable income of about $\$ 45$ a month - as much money as an entire family of four spent in 1940".. the paperbacking of America, o pesquisador norte-americano Kenneth C. Davis se debruça sobre o fenômeno das brochuras populares no país:

Antes de esses livros de baixo custo e de larga distribuição chegarem, somente os livros mais ra ros vendiam mais do que cem mil cópias [...] Do dia para a noite, a brochura mudou isso. De repente, um livro podia alcançar não centenas ou milhares de leitores, mas milhões deles, muitos dos quais nunca haviam sido donos de um livro (DAVIS, 1984, p.xii).?

Davis escreve que autores como J. D. Salinger e Jack Kerouac se tornaram emblemáticos para o fenômeno da brochura no Estados Unidos (DAVIS, 1984, p. 202). Os livros que mais faziam sucesso eram exatamente aqueles cujo público leitor eram os jovens, que também viviam um momento inédito: pela primeira vez na história, eles tinham dinheiro para gastar:

[...] essas crianças brancas e alienadas dos anos 50 eram a geração mais bem alimentada, bem vestida e bem educada da história. Eles ta mbém eram os mais ricos. [...] O adolescente médio tinha uma renda disponível de cerca de US\$ 45 por mês - a mesma quantidade de dinheiro que uma família de quatro gastava em 1940 (KALLEN, 2001, p. 29).
Os direitos da brochura de The catcher in the rye, lançada em 1953 pelo selo Signet, da New American Library (NAL), foram vendidos antes mesmo da publicação em capa dura em 1951. Davis rela ta a urgência do editor Victor Weybright para comprar os direitos da obra:

Numa sexta-feira à tarde eu tinha recebido uma cópia avançada de Catcher in the rye, de J. D. Salinger. Eu o li naquela tarde e entrei num suor frio pensando que os direitos de reimpressão seria m levados por um competidor se eu esperasse a té segunda-feira de manhã. Eu cacei Arthur Thornhill [publisher da Little, Brown] no telefone, fiz o acordo e descobri depois que havíamos chegado antes de todos, que só receberam a cópia avançada na segunda ou na terça-feira seguinte (DAVIS, 1984, p. 203). ${ }^{9}$

É a partir da publicação do livro em brochura que começam a surgir os primeiros relatos das restrições imposta por Salinger às edições de seus livros. De olho em um mercado que já consumia literatura pulp, os editores da Signet buscavam criar um livro que se encaixasse nessa cultura. $\mathrm{O}$ resultado foi uma capa que retrata o protagonista numa área burlesca de Nova York, com uma prostituta acendendo um cigarro, cartazes de mulheres com poucas roupas e os dizeres: "Esse livro pouco usual pode chocar você, vai fazer você rir e talvez quebre seu coração - mas você nunca se esquecerá dele". ${ }^{10}$
9. No original: “One Friday afternoon of J.D. Salinger's Catcher in the Rye. I read it that evening and went into a cold sweat lest the reprint rights should be seized by a competitor if I waited until Monday morning. I tracked [Little, Brown publisher] Arthur Thornhill down on the telephone, made a deal and discovered later that we had beaten the field, most of whom did not receive their advance copies until

10. No original: "This unusual book may shock you, will make you but you will never forget it". 
11. No original: "In fact, he would be happier if the book was distributed in mimeographed form. Of course, he had no control over the cover".

12. No original: “[...] it seems both too anonymous and too enigmatic for immediate understanding by anyone who has not already met Holden. Here then is a suggestion on our part. Let us show him coming down Broadway or Forty-Second Street expressing his pained reaction to people who LIKE movies, etc."
O editor da NAL Marc Jaffe relata, em entrevista a Davis, que Salinger não queria ilustrações na capa: "Na verdade, ele ficaria mais feliz se o livro fosse distribuído na forma mimeografada. Obviamente, ele não tinha controle sobre a capa" (DAVIS, 1984, p. 203). ${ }^{11}$ Em The paperback art of James Avati, Piet Schreuders e Kenneth Fulton relatam o processo de criação da capa da primeira edição em paperback. Salinger havia sido convidado pelo fundador da NAL, Victor Weybright, a criar um conceito para a capa, e ele teria proposto uma cena do carrossel do Central Park. O autor não queria que o rosto de Holden Caulfield ou de sua irmã fossem ilustrados, porque não os havia descrito no livro recomendou que Holden fosse retratado na cena de costas, com seu chapéu vermelho. Criador de outras capas da editora, Avati foi o artista escolhido para o trabalho, mas ele rejeitou a ideia do autor em carta para Weybright:

[...] parece muito anônima e muito enigmática para ser compreendida por qualquer um que não já tenha tido contato com Holden. Então, aqui está uma sugestão da nossa parte. Nos deixe mostrar ele descendo a Broadway ou a rua Quarenta Dois com sua reação irritada com pessoas que GOSTAM de filmes etc (SCHREUDERS; FULTON, 2005, p. 42). ${ }^{12}$

Para aprovar a versão de Avati, foi feita uma reunião com Salinger. O designer relata que convenceu Salinger quando os dois estava m sozinhos. "Eu disse: 'Olha, o que você quer, você quer vender? Esses caras devem saber como vender livros, então foda-se, vamos fazer isso!' E fizemos' (SCHREUDERS, FULTON, 2005, p. 42). ${ }^{13}$ A primeira tiragem da Signet foi de 350 mil cópias. O livro foi publicado pela NAL por dez anos (a capa teve pequenas variações), até 1963, quando a licença teria que ser renovada. $\mathrm{Na}$ mudança de editora foi criada a capa de Catcher in the rye que se tornaria a mais conhecida nos Estados Unidos a té os a nos 1990, quando a capa original, com desenho de E. Michael Mitchell, voltou a ser usada Oscar Dystel, diretor da Bantam relata a Davis o processo de compra dos direitos da brochura do livro:

Ele me perguntou se eu estaria interessado em discutir Salinger. Eu disse: "Estarei no próximo avião". Eu larguei tudo, fui para Boston, e perguntei a Arthur [Thornhill, publisher da Little, Brown] o que ele queria. Fechamos o negócio com um royalty de dois porcento por livro e Arthur me contou que Salinger tinha que aprovar a capa. Eu disse: "O que ele quiser. Faremos de papel kraft". Salinger mandou a mostras para nos mostrar que cor ele queria. Ele selecionou até a fonte. O "J" e o "D" são fontes diferentes (DAVIS, 1984, p. 203-204). ${ }^{14}$

Ao longo das décadas, outras versões das capas de The catcher in the rye foram publicadas nos Estados Unidos. As
13. No original: "Salinger and got alone together, and I said, Look, what do you want, you want some sales? These guys are supposed to know how to sell book, so screw it, let's do o we did it".

14. No original: "He asked me if I might be interested in discussing Salinger. I said, In be on the next airplane. dropped everything, went Boston, and asked Arthur hands on a two-cent-perhook roy a two-cent-perbook royalty and Arthur then told me that Salinger had to approve the cover. I said 'Anything he wants. We'll do it on plain brown paper. Salinger actually sent us a swatch to show us the color he wanted. He even selected the typeface. The $J$ and the were set in different types". 
15. No original: "The only copy allowed on the books, back or front, is the author name and the title. Nothing else at all: no quotes, no cover blurb, no biography". capas e contracapas, no entanto, seguiram as diretrizes do a utor, que não impôs o design criado por ele, mas estabeleceu regras claras, que devem ser aplicadas em todas as suas obras: "O único texto permitido, na capa ou contracapa, é o nome do a utor e o título. Nada mais: nenhuma citação, nenhum elogio à obra, nada de biografia" (PROSSER, 2010, s/n). ${ }^{15}$

Figura 2: Capa da primeira edição da Signet de The catcher in the rye, criada por James Avati

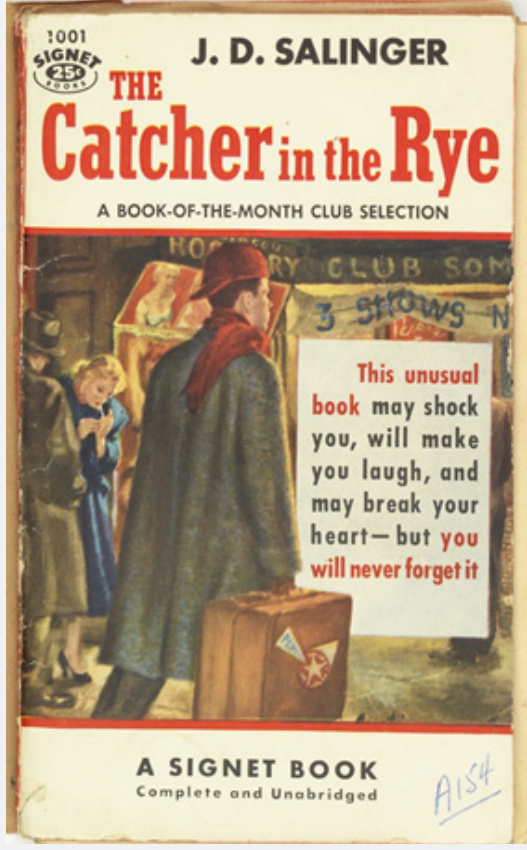

Fonte: National Archives of Australia
Figura 3: Capa de The catcher in the rye criada por Salinger para Bantam (dir.)

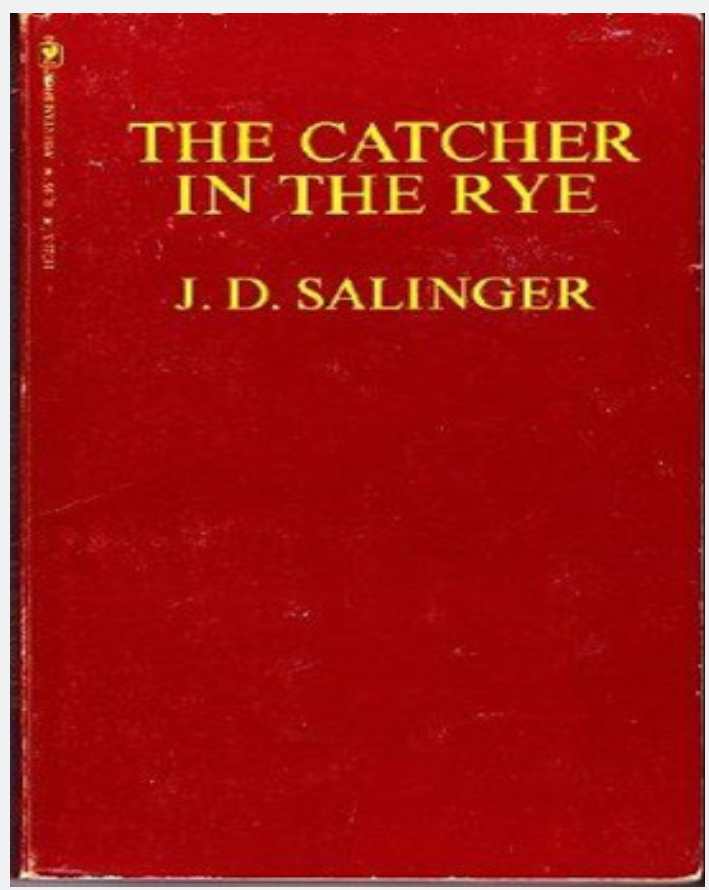

Fonte: Abe Books

A observação das edições da Signet e da Bantam para The catcher in the rye revelam a distância entre as representações da obra de Salinger. Enquanto a primeira é resultado de uma política editorial que valoriza o apelo comercial da obra, a segunda, minimalista, parece ser uma tentativa de apresentar o texto do autor sem "distrações". Não há espaço para a sinopse, o que poderia introduzir o leitor à obra, não 
16. O "livro de artista" é criado como um objeto de design, visto que $o$ autor se preocupa tanto com o "conteudo" quanto com a forma e faz desta uma formasignificante. Enquanto o autor de relação ao livro, o artista de livros tem uma atitude ativa já que ele é responsável pelo processo total de produção, porque não cria na dicotomia "continente-conteúdo", "significante-significado" (PLAZA, 1982, p.3) há apresentação, prefácio ou posfácio para fazer a mediação da obra ou de biografia que ofereceria contexto do autor para o leitor. A criação da capa da Bantam nos permite situar Salinger como um escritor que pretende ser não somente um "autor de texto", que "tem uma atitude passiva em relação ao livro", como coloca Júlio Plaza, ${ }^{16}$ mas um "autor de livro", com atitude ativa em relação ao processo editorial e cujo processo de criação se estende do texto ao livro. A impressão é que o autor estava de acordo com a posição de McKenzie de que "leitura de [...] signos bibliográficos pode realmente moldar nosso julga mento da obra de um autor" (2018, p. 32) e impôs restrições ao livro de forma que o texto fosse apresentado com o mínimo de interferência editorial possível.

\section{As publicações no Brasil}

Holden Caulfield foi apresentado ao leitor brasileiro em novembro de 1965, mas, para entender a chegada do adolescente norte-americano ao país, é preciso começar a história um pouco antes, com a criação da casa editorial que o recebeu, a Editora do Autor.

Projeto de Fernando Sabino, Rubem Braga e Walter Acosta, a Editora do Autor foi criada em 1960 a partir de uma percepção de Sabino que as editoras estavam "lança ndo livros demais, numa febre que prejudica autores e editores, uma vez que estes não trabalham os livros que publicam" (MEIRA, 1960, p. 6). O primeiro trabalho da editora foi O furacão sobre Cuba, de Jean-Paul Sartre, lançado com a presença do autor, em setembro de 1960 no Rio de Janeiro. O segundo lançamento da editora foi quádruplo. Uma antologia de crônicas de Paulo Mendes Campos, O cego de Ipanema; a "segunda edição a umentada" de Antologia poética, de Vinicius de Moraes; O homem nu, de Fernando Sabino; e a antologia de crônicas Ai de ti, Copacabana, de Rubem Braga.

$\mathrm{O}$ encontro do livro do autor norte-americano que gostaria de ter mais controle sobre a publicação de suas obras com os autores brasileiros que criaram uma editora para ditar os rumos editoriais das suas se deu graças à iniciativa de três diplomatas brasileiros, Jorio Dauster Álvaro Alencar e Antônio Rocha, de traduzir o romance. O repórter da Folha de S.Paulo, Cassiano Elek Machado, escreve que o trio enviou os originais da tradução para o Brasil por um a migo, que entrou em conta to com a Editora do Autor após ver uma propaganda da casa da lateral de uma kombi que circulava no Rio de Ja neiro (2003).

Publicado após a versão da editora Bantam, o livro já chegou ao Brasil com as restrições de Salinger para a criação da capa. O Jornal do Brasil, no qual Ferna ndo Sabino era colunista, funcionava como um canal de comunicação 
oficial da editora, e noticiou a preparação do livro e seu lançamento, com detalhes das dificuldades do trio em seguir as exigências do autor:

A tradução do título virou problema: primeiro porque não tinha bom correspondente em português e segundo porque Sallinger [sic] exerce uma vigilância feroz sobre tudo que diz respeito à sua obra. Ele vetou o título $O$ vigilante do abismo e propôs, como questão fechada, $O$ apanhador no campo do centeio [sic], pouco se importando que tenha ou não efeito comercial. Em Portugal, o livro foi traduzido para Agulha no palheiro e se tornou praticamente ilegível ao leitor brasileiro, pela linguagem coloquial e de gíria adotada em termos lusitanos. Entre outras esquisitices do autor, incluem-se a de não permitir a publicação de fotografias suas e de qualquer frase de elogio na capa do livro (GOMES, 1965, p. 10).

A disputa entre os editores e o autor mostra que o entendimento de Salinger de que os aspectos visuais e editoriais da obra deveriam ser "controlados" para que o foco do livro fosse o texto e não estratégias de edição ou vendas não ficou circunspecta à circulação nortea mericana do livro. O caso da tradução do título é mais um exemplo de como os signos podem moldar o julga mento de uma obra e de como Salinger não confiava em seus editores para tomar decisões sobre a apresentação de sua obra. Ele era, de fato, um "autor de livro".

Apesar de os editores não aprovarem o título exigido por Salinger, o livro foi publicado em setembro de 1965 no Rio de Janeiro, e foi sucesso imediato no país. Cerca de um mês após sua publicação, o título estava na lista de mais vendidos do Jornal do Brasil e era elogiado na revista Manchete, em especial pela qualidade da tradução: "Tratase de trabalho excepcional, talvez um dos mais honestos e perfeitos realizados no Brasil" (MANCHETE, 1965). O sucesso da obra foi tamanho que ele inspirou um pedido por mais traduções dos Estados Unidos, cuja literatura ainda não era a mplamente difundida no Brasil.

Há vários meses que dois volumes de escritores nortea mericanos contemporâneos vêm registrados nas listas de best-sellers das livrarias da Cidade. São O grupo, de Mary McCarthy, e O apanhador no campo de centeio, de Salinger. Isto prova o interesse do leitor brasileiro pela litera tura atual que se faz nos Estados Unidos. Portanto, não compreendemos que nossas editoras não lançam muito mais frequentemente autores norte-americanos. Dizem, agora, que um homem de negócios do Rio está criando uma editora dedicada quase que exclusivamente 
17. A casa editorial existiu até 1972, quando foi incorporada à Livraria José Olympio Editora a autores norte-americanos. Já não era sem tempo (JORNAL DO BRASIL, 1966, p. 7).

No ano seguinte à publicação de Apanhador no campo de centeio, a Editora do Autor perdeu seus dois editores mais famosos. Ferna ndo Sabino e Rubem Braga saíram da casa para abrir a Editora Sabiá, ${ }^{17}$ levando consigo a maior parte do catálogo. Walter Acosta ficou sozinho no comando da editora com alguns títulos, entre eles as três obras de Salinger que a editora havia publicado: $O$ apanhador no campo de centeio, Franny er Zoey e Nove estórias. Sem os autores fa mosos e seus a migos, a editora foi reduzindo seu catálogo ao longo dos anos, até se dedicar quase completa mente a Salinger. Publicado no Brasil exclusivamente pela editora, suas obras nem sempre estiveram disponíveis ${ }^{18}$ e foram dadas como esgotadas inúmeras vezes nas últimas décadas.

O percurso editorial do livro mudou em 2019, a no em que se comemorou o centenário de J. D. Salinger (19192010). Às vésperas de completar 60 a nos, a editora passou adiante os direitos de publicação dos livros de Salinger. André Conti, editor que ficou responsável pela obra do norte-americano na nova casa, fala do processo em entrevista:
Não é muito empolgante. O que aconteceu é que a gente está no ano do centenário, e a Editora do Autor avaliou que, depois de tanto tempo, e para aproveitar o centenário, para dar um certo fôlego para a obra, que eles não queriam mais por razões deles, eles decidiram que era hora de passar adiante para outra editora. Eles fizeram isso de comum acordo com o espólio da fa mília Salinger, que cuida diretamente da obra. Então, conversando com o espólio, eles chegaram à conclusão que era hora de ter uma editora que injetasse energia ânimo, que fizesse uma tradução nova, que investisse na divulgação do livro etc. Coisa que eles estavam, por razões deles, sem fazer. Eles nos procuraram, falaram dessa situação, que queriam passar o Salinger para outra editora e a gente fez uma proposta editorial de como a gente trabalharia.

A editora Todavia foi lançada na Festa Literária Internacional de Paraty (Flip) de 2017, com o livro O vendido, de Paul Beatty, um dos convidados do evento. A equipe é toda oriunda da Companhia das Letras, composta por André Conti, que trabalhou no local por onze a nos, Flávio Moura (cinco anos) e Leando Sarmatz (cinco anos). A eles se juntaram a agente literária Ana Paula Hisayama e o diretor comercial Marcelo Levy, que ta mbém têm passagem pela Companhia das Letras. A editora é financiada por 
Alfredo Setubal (Grupo Itaú) e Guilherme Affonso Ferreira (fundo de investimentos Teorema).

A edição da Todavia pa ra o livro de Salinger foi publicada em 18 de junho de 2019, com evento na Biblioteca Mário de Andrade, em São Paulo. Personalidades como Pedro Bial, Tati Bernardi, Marcio Black, Barbara Gancia Jorio Dauster e Bruninho Souza foram convidadas para compartilhar seus trechos preferidos. O tradutor Caetano W. Galindo, a preparadora de texto Márcia Copola e o editor André Conti participaram de um bate-papo sobre a produção editorial da obra.

Conti diz que o objetivo em levar o a utor para a Todavia foi "ter uma editora que injetasse energia, â nimo, que fizesse uma tradução nova, que investisse na divulgação do livro". O resultado foi, de fato, esse. A nova edição publicada no Brasil foi noticiada pela grande mídia nacional, com foco na relevância cultural do livro ("Apanhador no campo de centeio, que ga nha nova tradução, ajudou a criar imagem do adolescente", na Folha de S.Paulo), na nova tradução ("Clássico best-seller de J. D. Salinger, O apanhador no campo de centeio ganha nova tradução", em O Estado de $S$. Paulo) e nos livros inéditos do autor que serão publicados postumamente ("Filho de J.D. Salinger garante que textos inéditos do pai serão publicados", em $O$ Globo).

\section{Edições comparadas}

A chegada da edição da Todavia para o romance de Salinger possibilita analisar duas edições da mesma obra, cujas particularidades podem ser compreendidas como reflexos dos momentos históricos em que foram publicadas. A começar pela edição da Editora do Autor, chama a atenção a forma pública como os processos editoriais foram tratados, com detalhes sobre as dificuldades dos editores com Salinger noticiados diversas vezes no Jornal do Brasil. Por isso, sabemos que a composição da capa foi feita com restrições tanto no título quanto na questão visual: "Entre outras esquisitices do a utor, incluem-se a de não permitir a publicação de fotografias suas e de qualquer frase de elogio na capa do livro" (GOMES, 1965, p. 10).

A capa foi feita por Renato Vianna sobre ilustração de Anna Bella Geiger, que presumimos ter sido aprovada pelo autor. Em texto, somente o título (em inglês e em português) o nome do autor, da editora e a palavra "romance". $\mathrm{Na}$ orelha da capa, são citados, em inglês, outros livros de Salinger: Nine stories, Franny and Zooey e Raise high the roof beam: Carpenter and Seymour, an introduction. Na contracapa, fora $\mathrm{m}$ publicados os nomes do trio de tradutores. A orelha da contracapa não traz texto verbal. 
Figura 4: Capa da primeira edição de O apanhador no campo de centeio da Editora do Autor
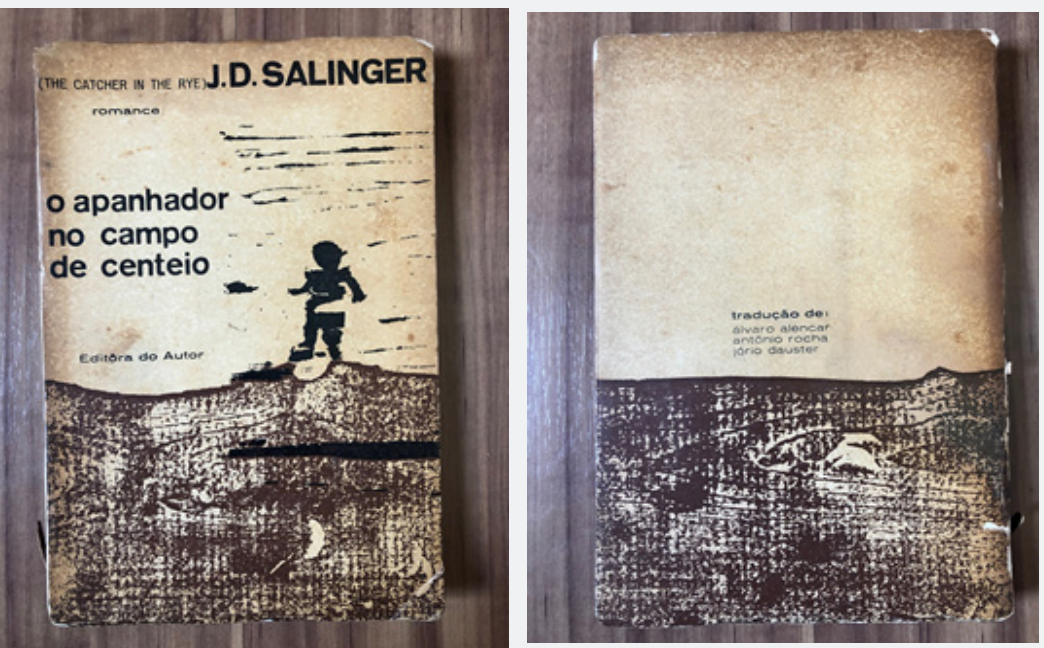

O descontentamento dos editores brasileiros com Salinger foi além das notícias que cercaram o lançamento do livro e viraram paratexto das primeiras edições no país. Apesar de seguirem as instruções do autor para a capa, os editores incluíram uma nota para explicitar a polêmica em torno do título escolhido:

Este livro foi traduzido e publicado em Portugal sob o título Agulha em palheiro. Os três jovens diplomatas brasileiros que fizeram a presente tradução escolheram

o título A sentinela do abismo. O Autor preferiu, entretanto, intitulá-lo O apanhador no campo de centeio (Editora do Autor, 1965).

Em entrevista ao blog Prosa, do jornal O Globo, o tradutor Jorio Dauster comenta a questão do título:

[...] fizemos longas listas de títulos alternativos até encontrarmos $A$ sentinela do abismo, em que respeitáva mos tanto o contexto quanto o conceito. Heureca! Que nada, a alegria durou pouco. Da agente literária de Salinger veio a ordem ríspida: ou se vertia o título literalmente ou era suspensa a venda dos direitos de tradução. Ordens do autor (DAUSTER, 2010, s/n).

No miolo há poucos paratextos. Avisos de direitos a utora is da obra em inglês e da tradução brasileira, alerta da proibição da circulação da obra em Portugal ou territórios portugueses ultra marinos, a dedica tória do livro ("A minha mãe”) e o colofão identificando a gráfica e a editora, a mbas do Rio de Janeiro. Nas edições subsequentes da Editora do Autor, o mesmo padrão foi repetido, apesar de as capas mudarem ao longo dos a nos. 
Figura 5: Capas das edições 4, 12, 16, 18 e 19 de Apa nhador, da Editora do Autor
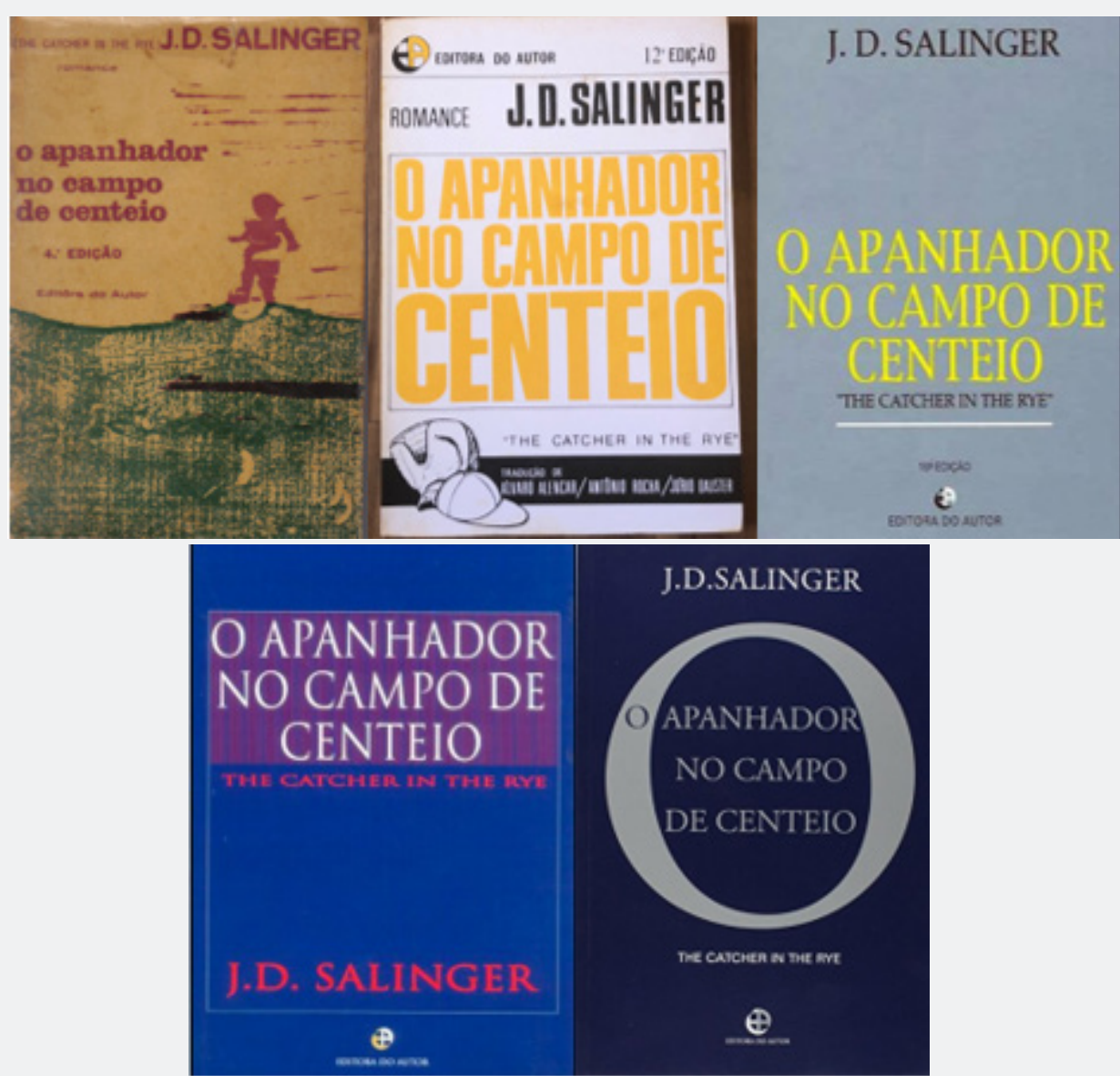

O pequeno número de paratextos confirma a posição de Salinger como um "autor de livro", de atitude ativa não somente em relação ao texto, mas aos aspectos materiais da sua obra - inclusive das traduções.
A edição da Todavia circulou com restrições similares às da versão da Editora do Autor. A solução da editora foi buscar a publicação da capa original, de E. Michael Mitchell, que já havia sido resgatada nos Estados Unidos com a autorização do a utor. André Conti fala da simplicidade do processo:

A gente apenas avisou: "Gostaríamos de fazer com a capa original". Eles apoia ra $\mathrm{m}$ desde o início. E foi isso. A gente queria trazer a capa que a gente adora. Que nunca saiu no Brasil, nunca foi publicado assim no Brasil. E aproveitando que a gente faria uma nova tradução, era a hora de trazer a capa icônica.

Assim, a edição da Todavia foi publicada com a imagem da primeira publicação nos Estados Unidos, adaptada por Pedro Inoue. Na capa e na lombada, há o título em português, o nome do autor e a marca da editora. Não há alusão ao gênero "romance", ao contrário do que é visto nas edições a tuais que levam a ilustração original dos EUA e na edição de 1965. Na contracapa, o nome da editora e o código de barras. 
Figura 6: Capa e contracapa da edição da Todavia para O apanhador no campo de centeio

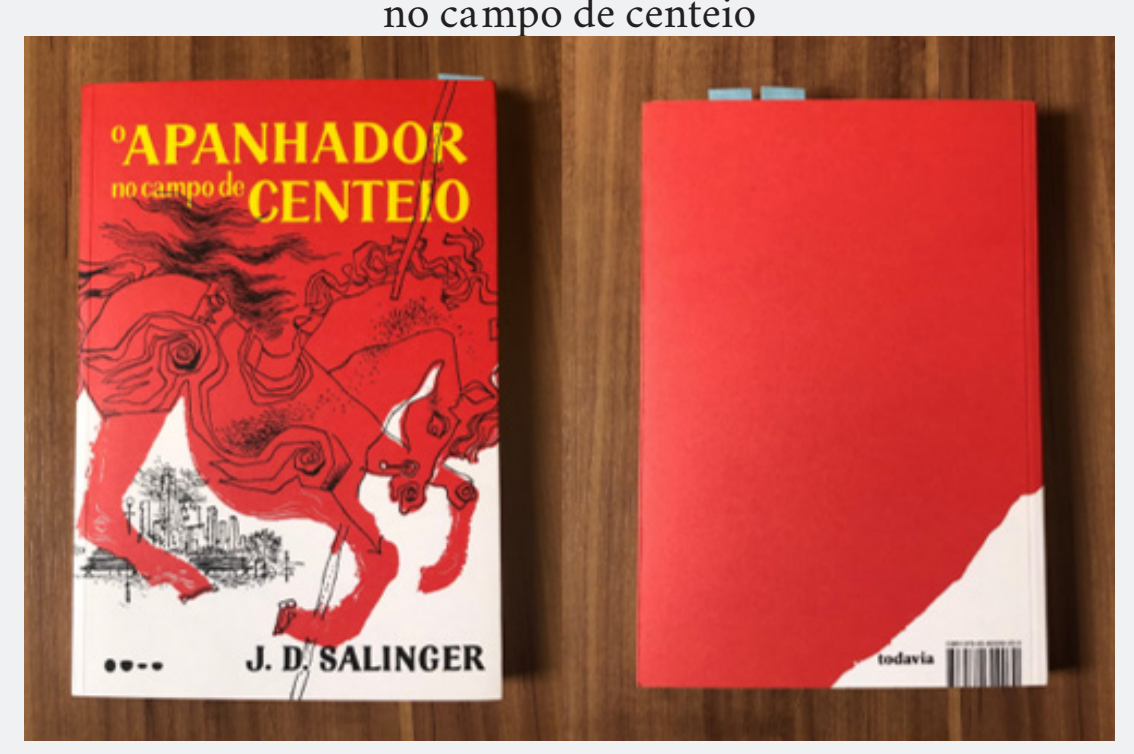

Apesar do uso de cor na capa e na guarda, o volume se aproxima da versão de 1965 (cuja capa foi impressa em preto e marrom) na pequena quantidade de paratextos. Antes do início do texto, somente a folha de rosto, que traz o nome do tradutor, Caetano W. Galindo, e a dedicatória ("Para minha mãe”). A ficha catalográfica é apresentada ao fim do livro, na mesma folha que o colofão.

Assim como ocorre com as edições norte-americanas após 1963 e as edições da Editora do Autor, a versão da Todavia é feita dentro das diretrizes restritivas do autor. A capa original, de E. Michael Mitchell já havia sido usada nos Estados Unidos quando o a utor era vivo, e se consolida como a única ilustração que pode estampar edições de livros do autor. A Todavia, que anunciou a publicação das outras três obras de Salinger (Nove histórias, Franny er Zooey e Raise high the roof beam, carpenters and Seymour: and introduction), ta mbém declarou que as outras capas serão tipográficas e seguirão as exigências do autor de limitar os paratextos.

No entanto, a Todavia encontra uma forma (limitada) de incluir paratextos à obra, perpassando a limitação imposta pelo autor. A editora enviou aos compradores da pré-venda um pôster com os paratextos da obra.

Figura 7: Pôster, marcador e cartão postal que acompanham livro da Todavia

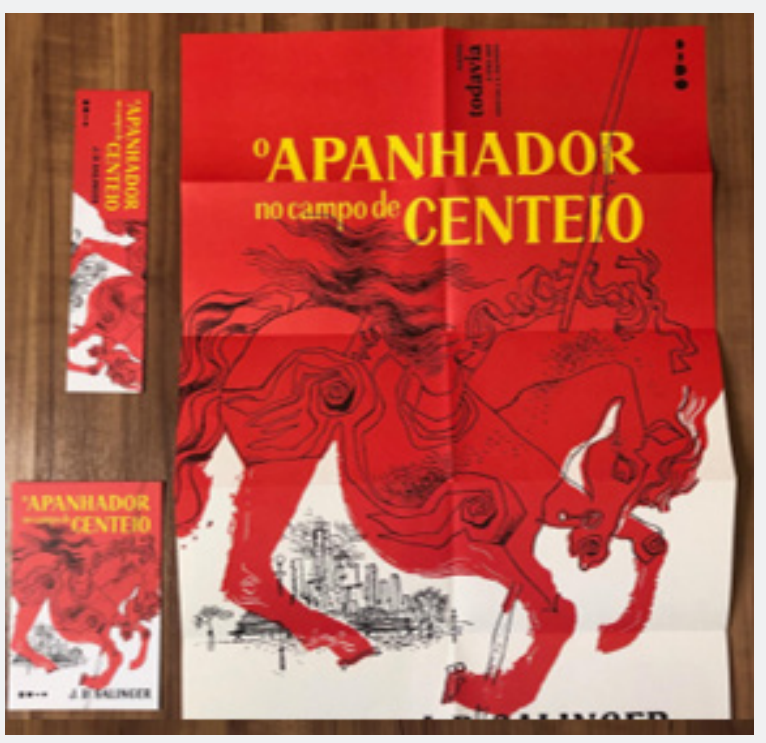




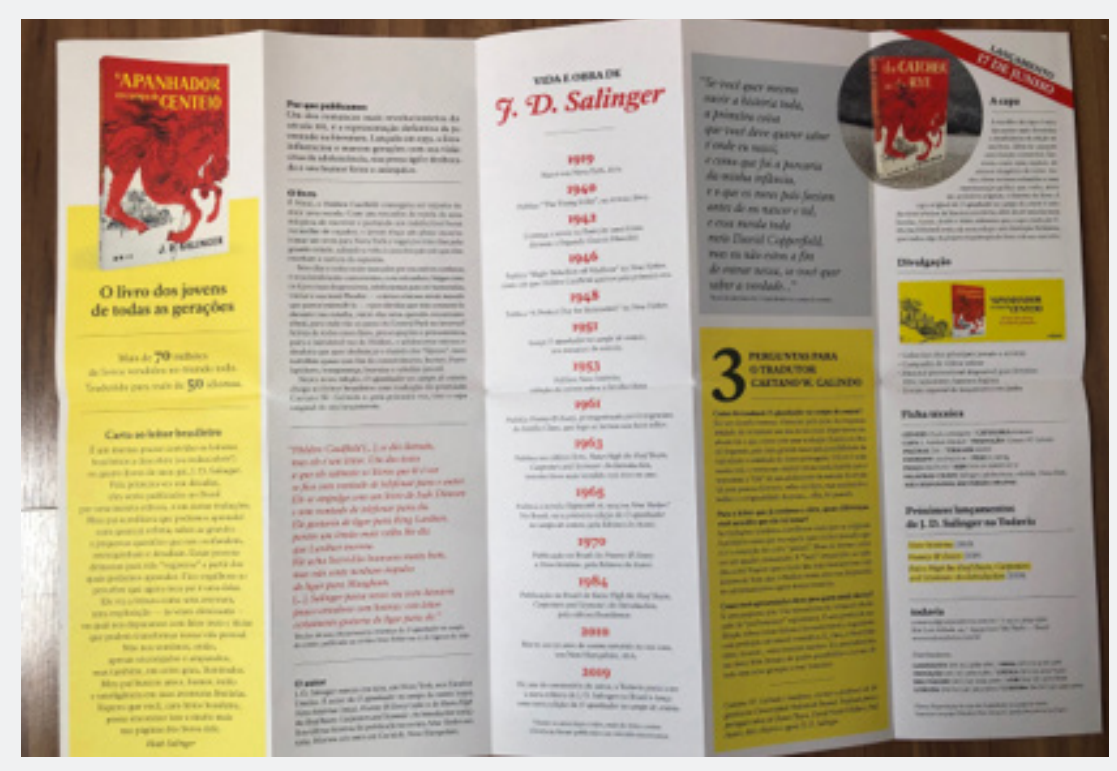

No encarte, uma carta de Matt Salinger, filho do autor, celebrando o centenário do pai, a sinopse do livro, trechos selecionados da obra, a biografia do autor, uma cronologia da vida do autor, a ficha técnica do livro, dados da estra tégia de divulgação da obra e uma curta entrevista com o tradutor Além desses textos, há uma explicação da abordagem que a casa editorial tem em relação à escolha da capa:

A escolha da capa é uma das partes mais divertidas e desafiadoras da edição de um livro. Além de cumprir uma função comercial - chamar a atenção nas livrarias -, a capa funciona como uma espécie de síntese imagética do texto: algo da trama, do clima ou do tema reduzidos a uma representação gráfica que, de certa forma, começa a contar, antes das primeiras páginas, a história dentro do livro. Ainda assim, há poucas capas unânimes, e discussões acaloradas costuma m ser comuns. O apanhador no campo de centeio é um caso à parte, e sua capa original é uma das mais icônicas da literatura moderna, além de ser uma das mais bonitas. Assim, desde o início sabíamos que a capa criada por E. Michael Mitchell em 1951 seria a da nossa edição. Amigo de longa data de J. D. Salinger, Mitchel criou uma ilustração fortíssima, que traduz algo da própria inquietação do livro e de seu personagem, com todo o cuidado para não revelar demais e limitar a imaginação do leitor (TODAVIA, 2019).

O discurso parece remeter ao que Salinger havia proposto para a capa quando foi convidado pelo fundador da NAL, Victor Weybright, a desenvolver um conceito para a primeira brochura do livro: uma capa que não mostra o rosto dos personagens, que não são descritos no livro, mas que a mbienta a história em Nova York, cidade retratada na ilustração.

\section{Considerações finais}

A a nálise das edições de The catcher in the rye, de J. D. Salinger, revela capítulos de histórias editoriais que ultrapassam a cronologia de publicações da obra em si. Publicado pela 
primeira vez em 1951 pela Little, Brown and Company, a história do colapso nervoso de Holden Caulfield foi recebida com entusiasmo pelos milhões de adolescentes norteamericanos nascidos durante ou após a Segunda Guerra Mundial. Com acesso a recursos fina nceiros a té então inéditos no país e com a recém-chegada brochura de baixo custo nos Estados Unidos, esses jovens fizera m do romance de Salinger um sucesso editorial e um marco cultural.

Essa intensa popularidade do romance talvez tenha sido o estopim para o crescente distancia mento de J. D. Salinger do olhar público. Mesmo a contragosto, o autor permite a publicação de uma brochura com edição apela tiva pela Signet, em 1953. No entanto, ele busca assumir maior controle dos aspectos materiais do livro em edições subsequentes, numa tentativa de assumir a mediação de sua própria obra com o público, assumindo decisões que são, historica mente, do editor, como estabelecendo capa e outros elementos paratextuais. Em 1963, é publicada nos EUA a versão da Bantam, cuja capa é desenvolvida pelo próprio autor, fazendo dele, de fato, um "autor de livro", que tem atitude ativa em relação ao objeto do livro. O histórico editorial de The cather in the rye mostra não somente a preocupação de um autor com o fato de que "as formas afetam o significado" (MCKENZIE, 2018, p.25), mas como o envolvimento de um Salinger no processo editorial afetou e afeta as edições publicadas.
A chegada do livro no Brasil é realizada por meio de uma editora que parece ter princípios compatíveis aos do autor. Criada por escritores que desejavam maior controle do processo editorial, em especial da divulgação, a Editora do Autor publica O apanhador no campo de centeio em 1965. Apesar disso, a edição não é feita sem percalços. As restrições impostas pelo autor causam estranhamento na chegada ao Brasil, em especial pela exigência da tradução literal do título. Se nos EUA o lançamento de The catcher in the rye marca um momento histórico pós-Segunda Guerra Mundial de afirmação da adolescência norte-americana, no Brasil o livro marca a também historicamente relevante crescente influência dos Estados Unidos sobre o país. Traduzida por diplomatas brasileiros nos EUA, a versão brasileira do livro ganha ares de importação cultural, o que parece ser confirmado pela enorme influência do país no Brasil contemporâneo.

No entanto, focando a análise nas publicações em si, o aspecto que salta aos olhos é a influência do autor. Salinger exerce controle sobre as edições de seus livros a té após sua morte, com a criação do J. D. Salinger Literary Trust, cujo objetivo é assegurar que seus desejos e restrições sejam seguidos em toda publicação que leva o seu nome. Salinger se revela um "autor de livro" exigente, que assume comando e responsabilidade pelos textos verbais e não verbais de sua obra. 
A análise das edições brasileiras tem que levar em consideração esse contexto de produção. Sem paratextos que apresentem o livro de forma adequada ao leitor que ainda não teve conta to com o autor ou sua obra, as edições da Editora do Autor e da Todavia só podem ser descritas como edições do possível. Dentro das limitações impostas, a Editora do Autor incluiu uma nota esclarecendo o título que considerou equivocado. Obrigada a seguir as restrições do autor, a Todavia "burla" as regras para incluir um encarte que, apesar de ter distribuição limitada, funciona como paratexto.

Numa época em que a popularidade da autopublicação e da publicação independente, com uma proximidade maior entre as etapas da produção editorial e o autor, estão em constante crescimento, o caso de Salinger funciona como caso exemplar da imposição do autor sobre a edição, assunto que demanda pesquisas mais aprofundadas.

\section{REFERÊNCIAS}

BLOOM, Harold. Introduction. IN: BLOOM, Harold (org.). Bloom's modern critical views: J. D. Salinger - new edition. Nova York: Infobase Publishing, 2008. p. 1-6.

DAUSTER, Jorio. No Brasil, "Apanhador" ia se chamar "Sentinela do abismo". 0 Globo, 21 de janeiro de 2010. Disponível em: <https:// glo.bo/2Xon5IP>. Acesso em: 21 Jun. 2019.
DAVIS, Kenneth C. Two-bit culture: the paperbacking of America. Boston: Houghton Mifflin, 1984. 409 p.

FOSBURGH, Lacey. J. D. Salinger speaks about his silence. The New York Times, 3 de novembro de 1974. p. 1. Disponível em: < https:// nyti.ms/2WPX920>. Acesso em: 17 Jun. 2019.

GOMES, Pedro. 0 vigilante do abismo. Jornal do Brasil, 13 de agosto de 1965. p. 10.

JORNAL DO BRASIL. Picadinho. Jornal do Brasil, 12 de janeiro de 1966. Caderno B, página 7.

KALLEN, Stuart A. Understanding 'The catcher in the rye'. San Diego (EUA): Lucent Books, 2001. 96 p.

MACHADO, Cassiano Elek. Editora lança caixa com três obras do autor de "0 apanhador". Folha de S.Paulo, 9 de abril de 2003. Disponível em: < http://bit.ly/2L76VXc> . Acesso em: 17 Jun. 2019.

MCKENZIE, D. F.. Bibliografia e sociologia dos textos. Trad. Fernanda Veríssimo. São Paulo: Edusp, 2018. 184p.

MEIRA, Mauritônio. Fernando Sabino cria editora experimental já vai lançar livros. Jornal do Brasil, 20 de agosto de 1960. p. 6.

MENAND, Louis, Holden at fifty. The New Yorker, 24 de setembro de 2001. Disponível em: < http://bit.ly/2MY7m96 > . Acesso em: 17 Jun. 2019. 
PLAZA, Julio. 0 livro como forma de arte (I). Arte em São Paulo. São Paulo, n. 6, abr.1982. 18p.

PROSSER, Simon. Exclusive: JD Salinger's new-look oeuvre. The Guardian, 29 de janeiro de 2010. Disponível em: <http://bit ly/2MY7HbS > Acesso em 17 Jun. 2019.

SALINGER, J.D.. 0 apanhador no campo de centeio. Trad. Álvaro Alencar, Antônio Rocha e Jorio Dauster. Rio de Janeiro: Editora do Autor, 1965.

SALINGER, J.D.. 0 apanhador no campo de centeio. Trad. Caetano W. Galindo. São Paulo: Todavia, 2019. 256 p.

SCHREUDERS, Piet; FULTON, Kenneth. The paperback art of James Avati. Rotterdam: 010 Publishers, 2005. 200 p.

WHITFIELD, Stephen J. Cherished and cursed: toward a social history of The catcher in the rye. The New England Quarterly. Vol. 70, N. 4 (Dez., 1997), p. 567-600. Disponível em: <http://bit.ly/2FIhrXI>. Acesso em: 17 Jun. 2019.

Recebido em: 10-12-2019. Aceito em: 18-06-2020 